\title{
Data Signal Detection of RUP View Online Interchange Based on Micro Message Platform

\author{
Binghui Liang
}

Department of students' work, Guilin University of Electronic Technology, Guilin, 541004, China

liang_binghui22@163.com

Keywords: WeChat platform; Ideological education; RUP view; B/S framework; XML language; Duty ratio

\begin{abstract}
In recent years, due to good user experience, open public platform and innovative communication forms, WeChat quickly goes into the people's work and life, much favored by college students. This paper introduces WeChat public platform into the process of ideological and political education, and establishes the mathematical model and algorithm of WeChat public platform interaction, and design interaction WeChat public platform of the ideological and political interaction. The platform uses RUP view design method, B/S framework, and XML to realize the data storage and exchange. Through the simulation of the platform, data duty ratio and the transmission rate is relatively stable in the platform operation. It provides a new mobile phone internet solution for the college students’ ideological and political education.
\end{abstract}

\section{Introduction}

Because WeChat public platform doesn't need to pay any fees, and its huge user group lets its powerful commercial value is valued more and more. WeChat service has become a new means of marketing. This paper introduces WeChat public platform into the interactive platform of ideological and political education to improve the students' ideological and political level through users' ideological and political experience [1, 2]. Using web function of WeChat internet realizes the ideological and political exchange interaction. The WeChat public not only improves the realtime and interaction of ideological and political education, but also can improve the utilization rate of students' mobile phone, so it is a new education of students.

\section{Overview of Network Ideological and Political Education WeChat Public Platform}

With the continuous development of the internet, the number of internet users has grown, and netizen influenced by the network culture also gradually increases. Due to the introduction of mobile phone web server, mobile phone internet becomes one of the main network tools among college students. As shown in Figure 1, mobile phone can develop a variety of functions using the Android system.

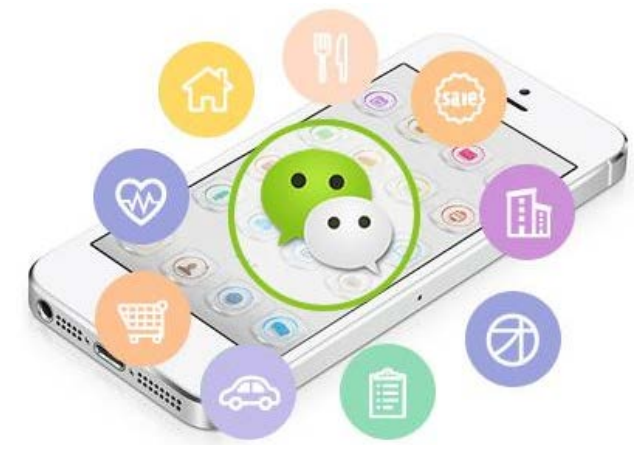

Fig.1: Schematic diagram of Android WeChat intelligent system

As shown in Figure 1 it is schematic diagram of Android WeChat intelligent system. Using WeChat public platform, mobile phone internet users can get all kinds of information, realizing the 
dating, shopping and other functions [3]. And it also plays a great influence on college students' ideological and political education.

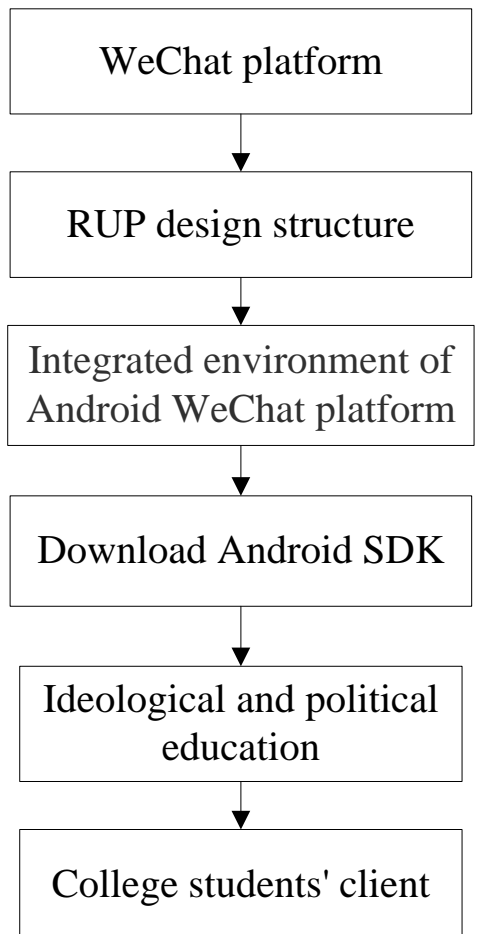

Fig.2: Android WeChat intelligent system design for ideological and political education

Figure 2 shows the designed Android smart WeChat communication system. As shown in Figure 2, the overall architecture of WeChat public platform adopts RUP structure [4]. And WeChat platform integrated environment is through Android SDK plug-in to realize, finally completes the design of WeChat public platform.

\section{Ideological Interactive Education Mathematics Model and Algorithm Design for WeChat Public Platform}

The influence of WeChat public platform on college students' network ideological and political is diverse, so the design of WeChat public platform needs to consider the students' political and ideological level. Through data mining it can extract psychological characteristics to complete the design of WeChat public platform [5, 6]. If $Y_{i}$ indicates the multivariate of college students' network political ideology, $f$ is the influence function, $X_{i}$ is network education scheme, $i$ is psychological characteristics change. So we can get the mathematical model as shown in formula 1.

$$
\begin{aligned}
& {\left[\begin{array}{c}
Y_{1 l} \\
\vdots \\
Y_{k l}
\end{array}\right]=\left[\begin{array}{ccc}
i_{11}^{1} & \cdots & i_{1 k}^{1} \\
\vdots & \ddots & \vdots \\
i_{k 1}^{1} & \cdots & i_{k k}^{1}
\end{array}\right]\left[\begin{array}{c}
Y_{1 l-1} \\
\vdots \\
Y_{k l-1}
\end{array}\right]+\cdots\left[\begin{array}{ccc}
i_{11}^{q} & \cdots & i_{1 k}^{q} \\
\vdots & \ddots & \vdots \\
i_{k 1}^{p} & \cdots & i_{k k}^{q}
\end{array}\right]\left[\begin{array}{c}
Y_{1 l-p} \\
\vdots \\
Y_{k l-p}
\end{array}\right]} \\
& +\left[\begin{array}{ccc}
f_{11}^{1} & \cdots & f_{1 g}^{1} \\
\vdots & \ddots & \vdots \\
f_{k 1}^{1} & \cdots & f_{k g}^{1}
\end{array}\right]\left[\begin{array}{c}
X_{1 l-1} \\
\vdots \\
X_{g l-1}
\end{array}\right]+\cdots\left[\begin{array}{ccc}
f^{w}{ }_{11} & \cdots & f_{1 g}^{w} \\
\vdots & \ddots & \vdots \\
f_{k 1}^{w} & \cdots & f_{k g}^{w}
\end{array}\right]\left[\begin{array}{c}
X_{1 l-1} \\
\vdots \\
X_{g l-1}
\end{array}\right] .
\end{aligned}
$$

So the computer feature extraction variables can be written in the formula 2.

$$
\begin{aligned}
& Y_{11} \square\left(i_{11}^{1} Y_{1 l-1}+\cdots i_{1 k}^{1} Y_{k l-1}\right)+\cdots+\left(i_{11}^{q} Y_{1 l-q}+\cdots e_{1 k}^{q} Y_{k l-q}\right) \\
& +\left(f_{11}^{1} X_{1 l-1}+\cdots f_{1 g}^{1} X_{g l-1}\right)+\cdots+\left(b_{11}^{w} X_{1 l-w}+\cdots b_{1 g}^{w} X_{g l-w}\right) .
\end{aligned}
$$

According to the self regression theory it can do multivariate analysis on the characteristic variables, and the error analysis is as shown in formula 3. 


$$
\varphi_{l}^{2}=\beta_{0}+\beta_{1} \lambda_{l-1}^{2} .
$$

$\lambda$ is heteroscedasticity based on $\lambda_{l-1}$ variation information, $\beta$ is error analysis.

$$
\varphi_{l}^{2}=\beta_{0}+\beta_{1} \lambda_{l-1}^{2}+\beta_{2} \lambda_{l-2}^{2}+\cdots+\beta_{q} \lambda_{l-q}^{2} .
$$

So the expression of feature extraction can be written as shown in formula 5 .

$$
T_{l}^{2}=\beta_{0}+\beta_{1} \lambda_{l-1}^{2}+\beta_{2} \lambda_{l-2}^{2}+\cdots+\beta_{q} \lambda_{l-q}^{2} .
$$

WeChat public platform is a interaction platform, according to the characteristics of college students' different political and ideological levels, it can use the data exchange to improve the students' political and ideological level [7]. This paper uses XML to realize the data exchange and storage of WeChat platform, and the main program is as follows:

$<$ ?xml version="1.0" encoding="utf-8"?>

$<$ bookstore $>$

$<$ book category="COOKING">

$<$ title lang="en" $>$ Everyday Italian $</$ title $>$

$<$ author $>$ Giada De Laurentiis $<$ /author $>$

$<$ year $>2014<$ year $>$

$<$ price $>30.00<$ price $>$

$<$ /book $>$

$<$ book category="CHILDREN">

$<$ title lang="en" $>$ Harry Potter $</$ title $>$

$<$ author $>$ J K. Rowling $<$ /author $>$

$<$ year $>2014<$ year $>$

\section{WeChat Public Platform Design and Research for Network Ideological and Political Education}

In order to verify the effectiveness and reliability of WeChat public platform interactive mathematics model designed in the second part, this paper uses mobile phone Android system, combined with XML information storage and exchange technology, to design the network ideological and political education platform $[8,9]$. The mobile phone display is as shown in Figure 3.

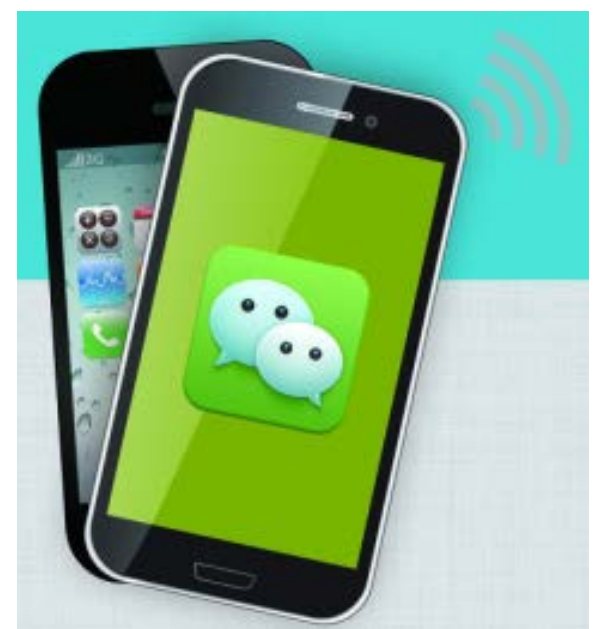

Fig.3: Schematic diagram of mobile phone WeChat platform

Figure 3 shows the general log diagram of WeChat. This paper uses the general program developed by WeChat platform and the intelligent Android system to design the WeChat public platform. The interface uses RUP structure mode, as shown in Figure 4. 


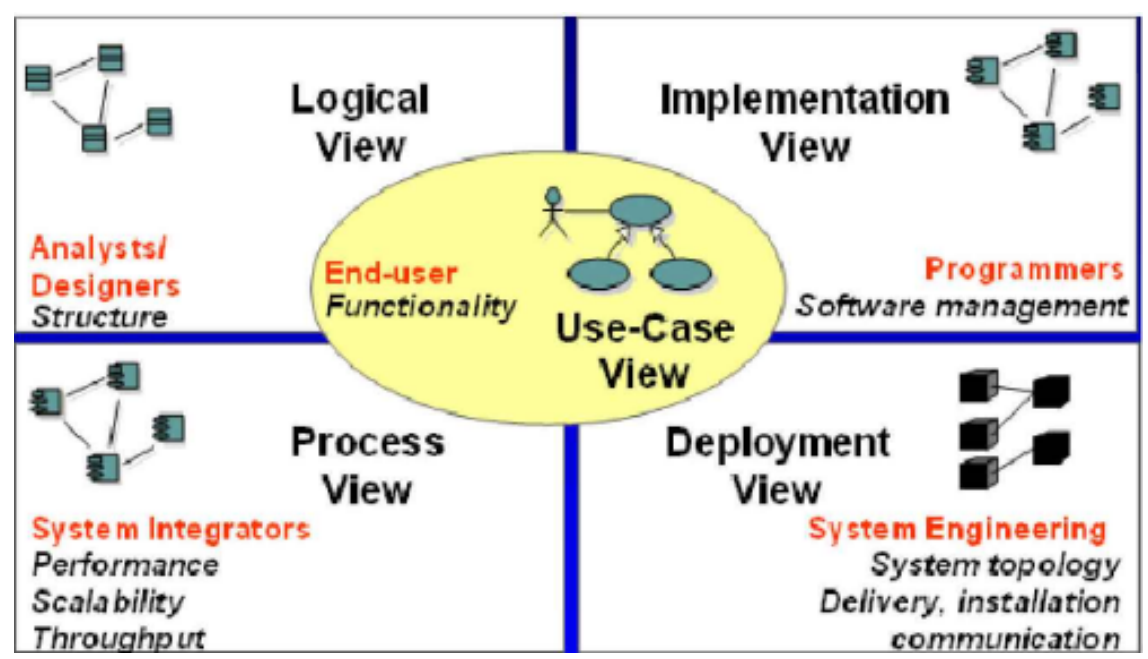

Fig.4: RUP structure mode for interface development

As shown in Figure 4, the system interface uses RUP structure mode, which means that the software developed by it is composed of component [10]. Component connection is through a welldefined interface. The framework model is object-oriented and focuses on modeling features.

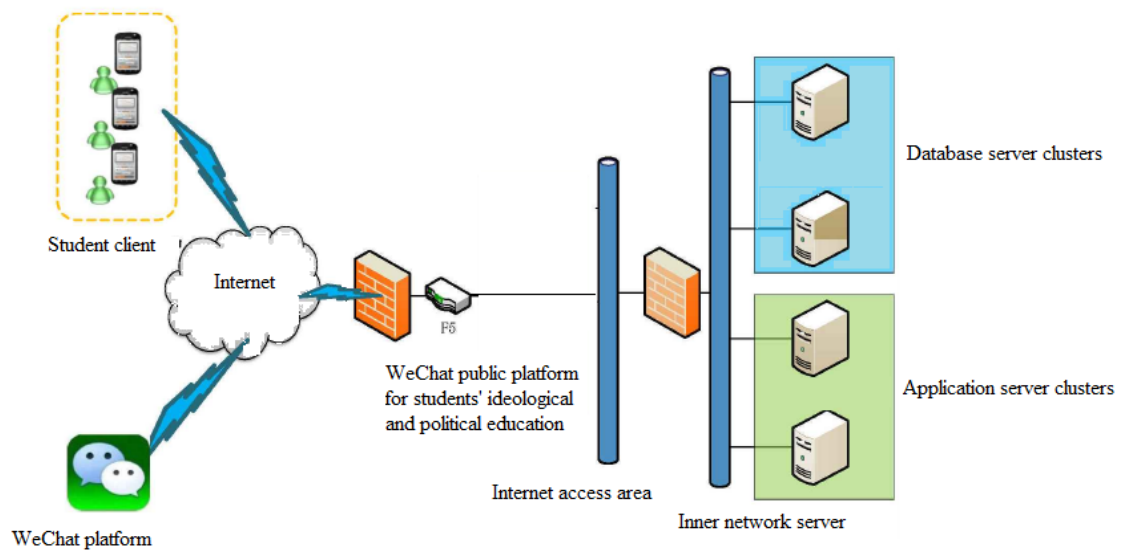

Fig.5: WeChat platform framework

Figure 5 shows the basic schematic of WeChat platform. The student client and WeChat platform is through internet to access to the internet. In the log platform of ideological education and data storage service it implants the firewall function [11]. The users use the internal server form. Finally it realizes the computer interaction function of political education.

Table 1: WeChat public platform design table

\begin{tabular}{lll}
\hline $\begin{array}{l}\text { Parameter } \\
\text { access_token }\end{array}$ & If it is a must? & Explain \\
& Yes & Calling interface \\
\hline & & document \\
touser & Yes & Ordinary users openid \\
msgtype & Yes & Support text, video, music \\
thumb_media_id & Video is a must, and music is not a must & Media file ID \\
\hline
\end{tabular}

Table 1 shows the main design table of WeChat platform. When the user logins, it needs to call interface program. Ordinary user touser is opedid format. Supporting data formats includes text, pictures, video and music. It realizes the interactive function of political and ideological education. 


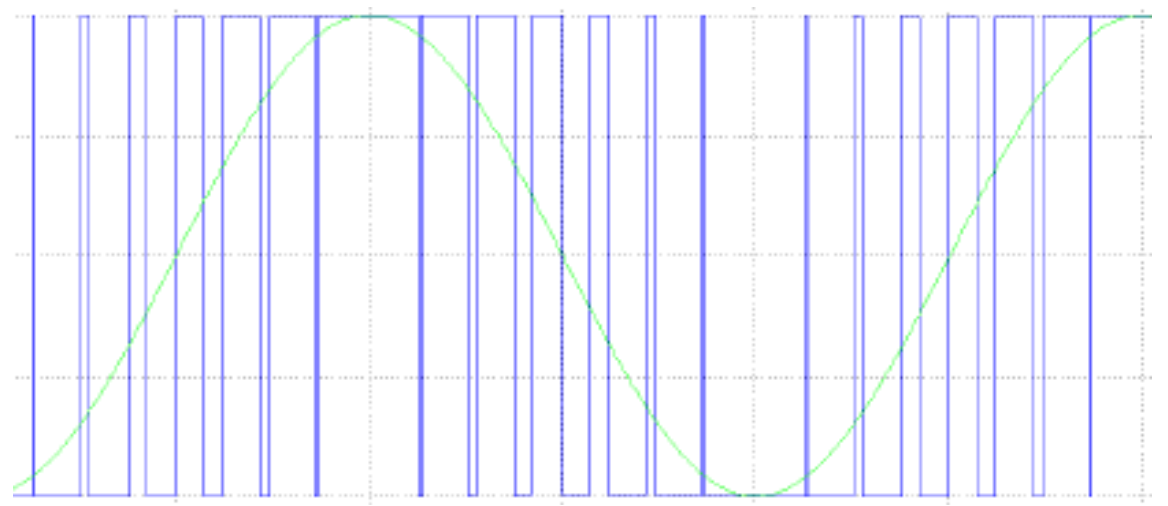

Fig.6: The data signal detection curve

In order to test the stability of the platform, this paper does statistical on a cycle of data processing duty ratio and the data operation flow, and draws the simulation curve through MATLAB simulation software [12]. From the chart we can see, the data doesn't produce large fluctuation, which verifies the stability of the system.

\section{Summary}

This paper establishes the interactive model of WeChat public platform, and introduces the feature extraction algorithm into the model, finally presents a new feature extraction algorithm for college students' psychological feature. This paper introduces the WeChat public platform into the college students' ideological and political education, and uses RUP view design method and the B/S framework to design WeChat public platform, finally realizes the data storage and communication using XML. Through the simulation of platform, the duty ratio and the transmission rate of data in the operation process is relatively stable. It means the platform is reliable, which satisfies the need of students' ideological and political education.

\section{Acknowledgments}

The work was supported by the two projects hosted by Liang Binghui. One is with the granted number [2013]16 from The Twelfth-five Year Plan Project of Guangxi education science plan with its project number 2012MSZ006 and its project name Platform Construction and Practice Research of Gratitude Education of Poor College Students Based on Digital Media Technology. The other is with the granted number[2012]53 from the key project of ideological and political education theory and Practice in Colleges and Universities in Guangxi with its project number 2013ZZ001 and its project name Integrated Platform Construction of Ideological and Political Education in College Students' Apartments Based on Digital Media Technology.

\section{References}

[1] Xiang Qingping. Review and suggestions: research on the domestic network political participation [J]. Journal of Party School of CPC Hangzhou Municipal Committee in recent years, 2012, 2(4): 57-58.

[2] Zhang Zaixing. Study on the network ideological and political education [M]. Beijing: Economic Science Press, 2012: 56-67.

[3] Zhao Xiang, Li Zhishu. Automatic generation realization based on invariant detection JUnit [J]. Computer application, 2011, 3(6): 319-321.

[4] Yuan Lin, Li Meiqing. Difficulties and countermeasures research on the ideological and political education in network communication process [J]. Journal of ideological and theoretical education, 2011, 3(6): 45-48.

[5] Jiang Xiaoli. Effectiveness evaluation system of the college students' network ideological and political education [J]. Education research, 2012, 3(6): 45-49. 
[6] Deng Zhuoming. Basic experience of college leading the social thought trends [J]. The college theory front, 2012, 3(11): 23-26.

[7] He Jie. Challenges and countermeasures of the patriotism education for college students in the new era: [J]. Journal of Henan Normal University (PHILOSOPHY AND SOCIAL SCIENCES EDITION), 2012, 3(4): 67-69.

[8] Wu Xingjie. Thought on the innovation of college students' patriotism education [J]. School party construction and ideological education, 2011, 2(1): 25-28.

[9] Sun Xiangjun. The main problems and countermeasures of patriotism education in colleges under the new situation [J]. Journal of Shandong Youth University of Political Science, 2012, 2(5): 78-81.

[10] Xu Ping. Thinking on college students' patriotism education in internet age [J]. Xiangtan Teachers College (SOCIAL SCIENCE EDITION), 2012, 6(3): 102-105.

[11] Xiao Xuebin, Julie. The influence and countermeasures of new media on the students' ideological and political education [J]. Ideological education study, 2011, 2(7): 82-85.

[12] Zhou Aoying, Jin Cheqing, Wang Guoren, Li Jianzhong. The uncertainty data management technology [J]. Journal of computers, 2011, 32(1):56-58. 